\title{
Does clinical improvement of symptomatic degenerative lumbar disease impact obesity?
}

\author{
Jacob R. Joseph, MD, Zishaan Farooqui, PhD, Brandon W. Smith, MD, Elyne N. Kahn, MD, \\ Xilin Liu, MD, Frank La Marca, MD, and Paul Park, MD
}

Department of Neurosurgery, University of Michigan, Ann Arbor, Michigan

\begin{abstract}
OBJECTIVE Obesity and low-back pain associated with degenerative spondylosis or spondylolisthesis are common comorbid conditions. Many patients report that the pain and disability associated with degenerative lumbar disease are key factors in their inability to lose weight. The aim of this retrospective study was to determine if there is an association between improved functional status and weight loss following a successful transforaminal lumbar interbody fusion (TLIF) procedure.
\end{abstract}

METHODS A retrospective cohort study of patients who underwent single-level TLIF was performed. Inclusion criteria were preoperative body mass index (BMI) greater than $30 \mathrm{~kg} / \mathrm{m}^{2}$, achievement of minimum clinically important difference in the Oswestry Disability Index (ODI, defined as improvement of 15 points), and minimum 1-year postoperative followup BMI. Preoperative and postoperative BMI, ODI, and visual analog scale (VAS) scores were compared. A subgroup analysis of patients who achieved substantial clinical benefit (SCB, defined as a net improvement of 18.8 points on the ODI) was also performed.

RESULTS A total of 56 patients met the inclusion criteria. The mean age of the study population was $55.6 \pm 13.7$ years. The mean preoperative BMI was $34.8 \pm 4.6 \mathrm{~kg} / \mathrm{m}^{2}$, the mean preoperative ODI was $66.2 \pm 10.1$, and the mean preoperative VAS score was $7.1 \pm 1.7$. The mean change in ODI was $-33.1 \pm 13.5(p<0.01)$ and the mean change in the VAS score was $-4.1 \pm 2.1(p<0.01)$. The mean change in BMl was $+0.15 \pm 2.1 \mathrm{~kg} / \mathrm{m}^{2}$ (range -4.2 to $\left.+6.5 \mathrm{~kg} / \mathrm{m}^{2} ; p=0.6\right)$. SCB was achieved in 46 patients on the ODI. The mean preoperative BMI for patients with SCB was $34.8 \pm 4.8 \mathrm{~kg} / \mathrm{m}^{2}$, and the mean postoperative BMI was $34.7 \pm 5.0 \mathrm{~kg} / \mathrm{m}^{2}$. The mean change in BMI was $-0.03 \pm 1.9 \mathrm{~kg} / \mathrm{m}^{2}(p=0.9)$.

CONCLUSIONS Despite successful surgical intervention via TLIF with achievement of improved function and pain, obese patients did not have significant change in weight postoperatively.

https://thejns.org/doi/abs/10.3171/2016.11.SPINE16973

KEY WORDS degenerative lumbar disease; minimum clinically important difference; obesity; substantial clinical benefit; transforaminal lumbar interbody fusion; weight loss; body mass index

$\mathrm{T}$ HE epidemic of obesity in the US is a well-established phenomenon, ${ }^{10}$ occurring in more than onethird of adults and approximately $17 \%$ of adolescents. ${ }^{21}$ The health and economic burden of obesity is expected to increase over the next decade, with trends predicting 65 million more obese adults in the US by 2030 , causing a potential increase in medical costs of \$48-\$66 billion per year. ${ }^{24}$ Obesity is associated with several comorbidities, and is a major burden on quality of life., ${ }^{9,16,17}$

Low-back pain is also an extremely common complaint. ${ }^{2}$ In fact, it is the fifth most common reason for physician visits in the US. ${ }^{3}$ Given the prevalence of both obesity and low-back pain, it is natural that they are shared comorbid conditions in a large number of the population.
Although there is some evidence of an association between lumbar spine disease and obesity, ${ }^{1,8}$ the nature of that association is complex..$^{15}$ Twin studies have suggested that there may not be a direct causal relationship between the 2 conditions. ${ }^{6}$ There is likely a 2 -way relationship between spine pathology and obesity, whereby the presence of obesity exacerbates back pain, but back pain's impact on quality of life may also predispose obese individuals to a sedentary lifestyle that is not conducive to losing weight and reducing the health burden of obesity. ${ }^{17,20}$ Indeed, severity of pain has been shown to be associated with suboptimal weight loss. ${ }^{19}$ Many patients report that the pain and disability associated with degenerative lumbar disease are key factors in their inability to lose weight. 
While most low-back pain is believed to be associated with muscular strain or sprain, degenerative lumbar spondylosis and degenerative spondylolisthesis are also commonly believed to cause low-back pain. Previous studies have estimated that disc and facet degeneration account for approximately $10 \%$ of patients with back pain, while spondylolisthesis accounts for $2 \% .^{14}$ In another study, the prevalence of degenerative spondylolisthesis was $2.7 \%$ in males and $8.4 \%$ in females. ${ }^{13}$ From a surgical treatment standpoint, transforaminal lumbar interbody fusion (TLIF) is a commonly used technique to treat refractory cases of degenerative spinal disease and has been shown to improve functional status and long-term pain reduction, even in obese patients. ${ }^{18,23}$ Previous studies have defined a minimum clinically important difference (MCID) in TLIF as an improvement in the Oswestry Disability Index (ODI) of 14.9 points. ${ }^{22}$ A substantial clinical benefit (SCB) was previously defined in lumbar arthrodesis as a net improvement of 18.8 points. ${ }^{12}$ However, it is unknown whether such improvements are associated with significant weight loss, presumably due to improved function and activity level. The aim of this retrospective study was to determine if there is an association between improved functional status and weight loss following a successful TLIF procedure.

\section{Methods}

Following approval by the University of Michigan IRB, we performed a retrospective cohort study via medical record review of patients who underwent single-level TLIF. Inclusion criteria were a preoperative body mass index (BMI) greater than $30 \mathrm{~kg} / \mathrm{m}^{2}$, improvement in the ODI of at least 15 points, and minimum 1-year postoperative follow-up BMI. Data were also collected on patients who did not show improvement in the ODI of at least 15 points (patients who did not achieve MCID). ODI and BMI were offset to allow patients to have time after activity restrictions were lifted to experience meaningful weight loss. Demographic data including age at surgery and sex were recorded, as were level of fusion and indication for procedure. Preoperative BMI, ODI, and visual analog scale (VAS) score for pain were recorded. Preoperative BMI was graded into Class I, Class II, and Class III obesity. Class I was defined as BMI of $30.0-34.9 \mathrm{~kg} / \mathrm{m}^{2}$, Class II was defined as a BMI of $35.0-39.9 \mathrm{~kg} / \mathrm{m}^{2}$, and Class III was defined as a BMI of $40.0 \mathrm{~kg} / \mathrm{m}^{2}$ or greater. Postoperative ODI and VAS scores at 3 months and 1 year were recorded. Postoperative BMI at 1 year was also recorded.

Statistical analysis was performed utilizing GraphPad Prism software, version 6 (GraphPad Software, Inc.). Paired 2-tailed t-tests were used to compare preoperative and postoperative BMI, ODI, and VAS scores. Subgroup analyses of patients with Class I and Class II/III obesity were performed using paired 2-tailed t-tests. Subgroup analyses of males and females were also performed using paired 2-tailed t-tests. An unpaired 2-tailed t-test was used to compare BMI change in patients with and without achievement of MCID. A statistical significance level of $p$ $<0.05$ was set for this analysis.

\section{Results}

A total of 135 obese patients were identified as having undergone single-level TLIF during the study period. Forty-three patients were excluded due to lack of followup ODI or BMI, and 36 patients were excluded due to not meeting MCID. Fifty-six patients met the inclusion criteria. Four patients did not have follow-up VAS data. The mean age of the study population was $55.6 \pm 13.7$ years. There were 37 females (66.1\%) and 19 males (33.9\%). Forty-one patients had a primary diagnosis of spondylolisthesis, while 15 had a primary diagnosis of degenerative disc disease. The majority of patients underwent fusion at L4-5 (30 patients, 53.6\%) or L5-S1 (20 patients, 35.7\%). Two patients underwent fusion at L3-4, 2 at L2-3, 1 at L1-2, and 1 at L6-S1. There were 37 patients $(66.1 \%)$ with Class I obesity, 10 (17.9\%) with Class II obesity, and 9 patients $(16.1 \%)$ with Class III obesity.

Changes in BMI, ODI, and VAS for the entire cohort are shown in Table 1. The mean preoperative BMI was $34.8 \pm 4.6 \mathrm{~kg} / \mathrm{m}^{2}$ (range $\left.30.1-50.6 \mathrm{~kg} / \mathrm{m}^{2}\right)$. The mean preoperative ODI was 66.2 \pm 10.1 (range 44-88), and the mean preoperative VAS score was $7.1 \pm 1.7$ (range 4-10). The mean 3-month ODI was $33.0 \pm 16.4$ (range 0-60) and the mean 3-month VAS score was $3.0 \pm 2.0$ (range 0-8). The mean 1-year BMI was $34.9 \pm 4.9 \mathrm{~kg} / \mathrm{m}^{2}$ (range 28.5 $\left.48.4 \mathrm{~kg} / \mathrm{m}^{2}\right)$. The mean change in ODI was $-33.1 \pm 13.5(\mathrm{p}$ $<0.01)$ and the mean change in VAS score was $-4.1 \pm 2.1$ $(\mathrm{p}<0.01)$. The mean change in BMI was $+0.15 \pm 2.1 \mathrm{~kg} /$ $\mathrm{m}^{2}$ (range -4.2 to $+6.5 \mathrm{~kg} / \mathrm{m}^{2} ; \mathrm{p}=0.6$ ); changes in BMI are represented in Fig. 1.

There were 46 patients who achieved SCB on the ODI at 3-month follow-up. The mean preoperative BMI for SCB patients was $34.8 \pm 4.8 \mathrm{~kg} / \mathrm{m}^{2}$, and mean postoperative BMI was $34.7 \pm 5.0 \mathrm{~kg} / \mathrm{m}^{2}$. The mean change in BMI in this group was $-0.03 \pm 1.9 \mathrm{~kg} / \mathrm{m}^{2}(\mathrm{p}=0.9)$.

For patients with Class I obesity, the mean ODI improvement was $32.3 \pm 12.6(\mathrm{p}<0.01)$ and the mean VAS score improvement was $4.3 \pm 2.2(\mathrm{p}<0.01)$. BMI change for Class I obesity was $+0.29 \pm 2.1 \mathrm{~kg} / \mathrm{m}^{2}(\mathrm{p}=0.4)$. For patients with Class II/III obesity, mean ODI improvement was $34.8 \pm 15.3(\mathrm{p}<0.01)$ and mean VAS score improve-

TABLE 1. Changes in BMI, ODI, and VAS scores from preoperative baseline to 3-month and 1-year follow-up visits in 56 patients after single-level TLIF

\begin{tabular}{|c|c|c|c|c|c|c|c|}
\hline \multirow[b]{2}{*}{ Scale } & \multirow{2}{*}{$\begin{array}{l}\text { Preop Mean } \\
\quad \pm \text { SD }\end{array}$} & \multicolumn{2}{|c|}{ 3-Mo Follow-Up } & \multicolumn{2}{|c|}{ 1-Yr Follow-Up } & \multicolumn{2}{|c|}{ Change } \\
\hline & & Mean \pm SD & $p$ Value & Mean \pm SD & $p$ Value & Mean \pm SD & $\mathrm{p}$ Value \\
\hline BMI $\left(\mathrm{kg} / \mathrm{m}^{2}\right)$ & $34.8 \pm 4.6$ & - & & $34.9 \pm 4.9$ & 0.60 & $+0.15 \pm 2.1$ & 0.60 \\
\hline ODI & $66.2 \pm 10.1$ & $33.0 \pm 16.4$ & $<0.01$ & $37.3 \pm 23.1$ & $<0.01$ & $-33.1 \pm 13.5$ & $<0.01$ \\
\hline VAS & $7.1 \pm 1.7$ & $3.0 \pm 2.0$ & $<0.01$ & $3.6 \pm 2.3$ & $<0.01$ & $-4.1 \pm 2.1$ & $<0.01$ \\
\hline
\end{tabular}




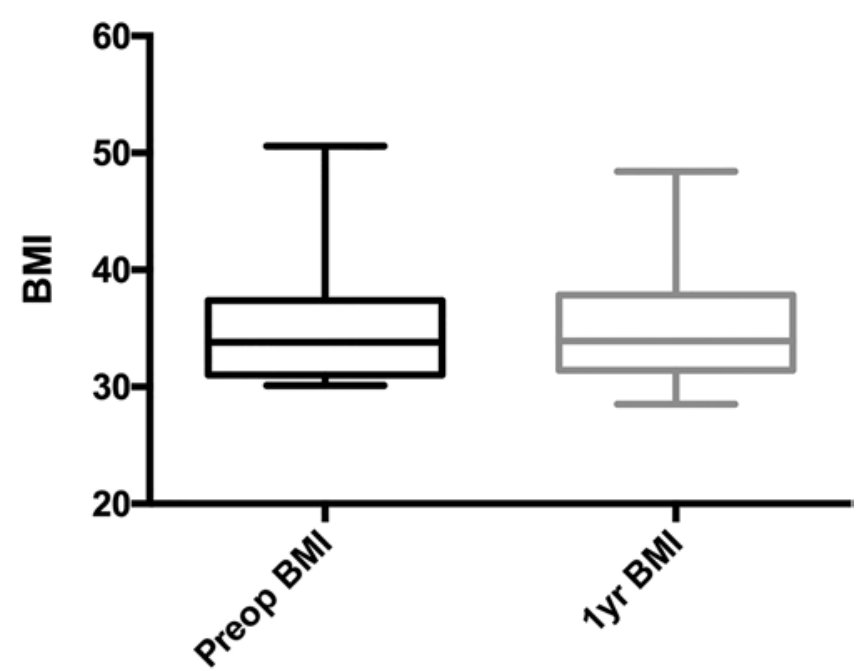

FIG. 1. Box-and-whisker plot of BMI preoperatively and at 1-year follow-up.

ment was $3.7 \pm 1.9(\mathrm{p}<0.01)$. BMI change for Class II/III obesity was $-0.12 \pm 2.2 \mathrm{~kg} / \mathrm{m}^{2}(\mathrm{p}=0.8)$. Neither change in BMI in males $\left(+0.29 \pm 2.4 \mathrm{~kg} / \mathrm{m}^{2} ; \mathrm{p}=0.6\right)$ or females $\left(+0.08 \pm 2.0 \mathrm{~kg} / \mathrm{m}^{2} ; \mathrm{p}=0.8\right)$ was significant.

At 1-year follow-up, the mean ODI was insignificantly changed when compared with the 3-month follow-up ( $\mathrm{p}=$ $0.07)$. However, the mean VAS score at 1-year was significantly increased $(\mathrm{p}=0.03)$. Compared with preoperative ODI and VAS scores, there was still a significant decrease in ODI $(\mathrm{p}<0.01)$ and VAS $(\mathrm{p}<0.01)$ scores at 1-year follow-up. These data are represented graphically in Figs. 2 and 3 .

Of the 36 patients who did not meet MCID, the mean age was 51.3 years, and the mean preoperative BMI was $34.9 \pm 5.6 \mathrm{~kg} / \mathrm{m}^{2}$. Sixteen $(44.4 \%)$ were female, and 20 $(55.6 \%)$ were male. The mean ODI change was $-3.4 \pm 8.9$ (range -14 to 18). In 25 patients with follow-up BMI data, the mean BMI change was $+0.93 \pm 2.8 \mathrm{~kg} / \mathrm{m}^{2}(\mathrm{p}=0.1)$. There was no significant difference in BMI change between patients who did and did not achieve MCID ( $\mathrm{p}=0.2)$.

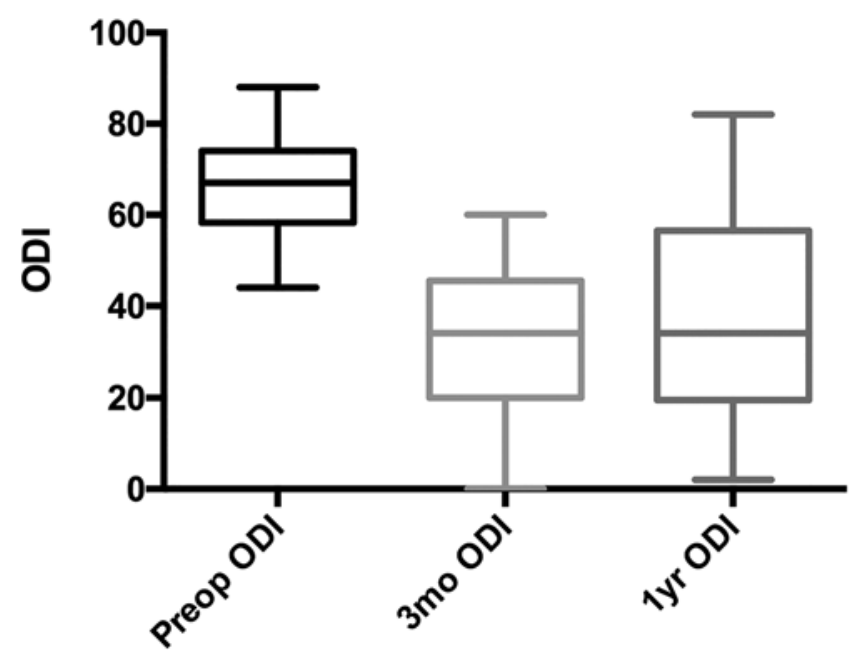

FIG. 2. Box-and-whisker plot of ODI preoperatively and at 3-month and 1-year follow-up.

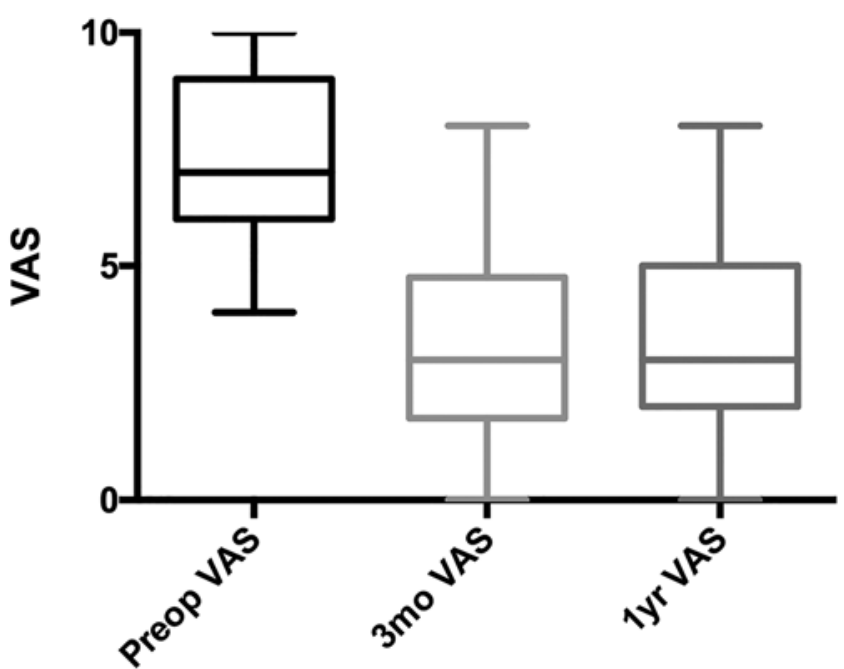

FIG. 3. Box-and-whisker plot of VAS preoperatively and at 3-month and 1-year follow-up.

\section{Discussion}

MCID is defined as the smallest change in an outcome measure that is important to a patient, and is believed to be the threshold for meaningful clinical improvement. ${ }^{5}$ Previous studies have defined MCID of the ODI in lumbar degenerative disease to be a 12.8-point improvement, although for TLIF specifically, it was defined as a 14.9-point improvement. ${ }^{4,22}$ However, MCID is not necessarily defined by standard methodology, and may therefore be variable. Parker et al. calculated MCID in ODI after TLIF using 4 different methods, and found that MCID ranged from 11 to 22.9 points, depending on the calculation used. ${ }^{22}$ Because MCID is, by definition, the "floor" of success, the concept of SCB has been thought to be a more useful determinant of truly meaningful changes in outcome measures. Both MCID and SCB are importantly more useful as measures for individuals, rather than for populations. $^{12}$

Several reports suggest that obesity may have an adverse impact on clinical outcomes following spinal fusion surgery. ${ }^{7,8,11}$ However, the impact of surgery itself on weight changes in obese patients is unknown. In this retrospective cohort study, we aimed to address whether symptomatic relief following TLIF was associated with weight loss, as measured by BMI. For patients who achieved MCID on the ODI, we found no significant change in BMI. This change in ODI remained stable from 3-month follow-up until 1-year follow-up. Similarly, there was no significant change in BMI when specific classes of obesity were evaluated. Even when patients achieved SCB, which is believed to be a significantly higher level of meaningful clinical improvement, no relevant changes in BMI were observed. These results suggest that obese patients do not lose weight, even with improved function and less pain, as evidenced by the improved postoperative VAS scores. It should be noted that obesity is a complex problem with a multitude of contributing factors. To our knowledge, this report is the first of its kind to investigate an association between functional improvement in lumbar degenerative disease and weight loss. 
This study also brings to light the possibility that there may be a missed opportunity for weight loss in these patients. With the significant increase in their mobility and decrease in pain, these obese patients may be in a good position to enter aggressive weight loss programs after they have been removed from postsurgical activity restrictions.

There are limitations to this study. This was a retrospective cohort study, and is therefore subject to inherent biases including selection bias and loss to follow-up. In addition, this study was limited to a 1-year follow-up, which does not account for long-term weight changes.

\section{Conclusions}

Despite successful surgical intervention via TLIF, with subsequent improvement in function and pain, obese patients did not experience significant weight loss postoperatively. Further prospective studies are needed to validate these data, and to explore novel means to encourage weight loss after TLIF surgery.

\section{References}

1. Anandacoomarasamy A, Caterson I, Sambrook P, Fransen M, March L: The impact of obesity on the musculoskeletal system. Int J Obes 32:211-222, 2008

2. Andersson GB: Epidemiological features of chronic lowback pain. Lancet 354:581-585, 1999

3. Chou R, Qaseem A, Snow V, Casey D, Cross JT Jr, Shekelle P, et al: Diagnosis and treatment of low back pain: a joint clinical practice guideline from the American College of Physicians and the American Pain Society. Ann Intern Med 147:478-491, 2007

4. Copay AG, Glassman SD, Subach BR, Berven S, Schuler TC, Carreon LY: Minimum clinically important difference in lumbar spine surgery patients: a choice of methods using the Oswestry Disability Index, Medical Outcomes Study questionnaire Short Form 36, and pain scales. Spine J 8:968-974, 2008

5. Copay AG, Subach BR, Glassman SD, Polly DW Jr, Schuler TC: Understanding the minimum clinically important difference: a review of concepts and methods. Spine J 7:541-546, 2007

6. Dario AB, Ferreira ML, Refshauge KM, Lima TS, Ordoñana JR, Ferreira PH: The relationship between obesity, low back pain, and lumbar disc degeneration when genetics and the environment are considered: a systematic review of twin studies. Spine J 15:1106-1117, 2015

7. De la Garza-Ramos R, Bydon M, Abt NB, Sciubba DM, Wolinsky JP, Bydon A, et al: The impact of obesity on short- and long-term outcomes after lumbar fusion. Spine (Phila Pa 1976) 40:56-61, 2015

8. Fanuele JC, Abdu WA, Hanscom B, Weinstein JN: Association between obesity and functional status in patients with spine disease. Spine (Phila Pa 1976) 27:306-312, 2002

9. Flamme $\mathrm{CH}$ : [Obesity and low back pain-biology, biomechanics and epidemiology]. Orthopade 34:652-657, 2005 (Ger)

10. Flegal KM, Carroll MD, Kit BK, Ogden CL: Prevalence of obesity and trends in the distribution of body mass index among US adults, 1999-2010. JAMA 307:491-497, 2012

11. Giannadakis C, Nerland US, Solheim O, Jakola AS, Gulati M, Weber C, et al: Does obesity affect outcomes after decompressive surgery for lumbar spinal stenosis? A multicenter, observational, registry-based study. World Neurosurg 84:1227-1234, 2015
12. Glassman SD, Copay AG, Berven SH, Polly DW, Subach BR, Carreon LY: Defining substantial clinical benefit following lumbar spine arthrodesis. J Bone Joint Surg Am 90:18391847,2008

13. Jacobsen S, Sonne-Holm S, Rovsing H, Monrad H, Gebuhr P: Degenerative lumbar spondylolisthesis: an epidemiological perspective: the Copenhagen Osteoarthritis Study. Spine (Phila Pa 1976) 32:120-125, 2007

14. Jarvik JG, Deyo RA: Diagnostic evaluation of low back pain with emphasis on imaging. Ann Intern Med 137:586-597, 2002

15. Koulischer $\mathrm{S}$, Cadière $\mathrm{B}$, Cadière GB, Fabeck L: [Evolution of low back pain after bariatric surgery.] Rev Med Brux 36:147-151, 2015 (Fr)

16. Larsson UE: Influence of weight loss on pain, perceived disability and observed functional limitations in obese women. Int J Obes Relat Metab Disord 28:269-277, 2004

17. Larsson UE, Mattsson E: Perceived disability and observed functional limitations in obese women. Int J Obes Relat Metab Disord 25:1705-1712, 2001

18. Lau D, Khan A, Terman SW, Yee T, La Marca F, Park P: Comparison of perioperative outcomes following open versus minimally invasive transforaminal lumbar interbody fusion in obese patients. Neurosurg Focus 35(2):E10, 2013

19. Masheb RM, Lutes LD, Kim HM, Holleman RG, Goodrich DE, Janney CA, et al: Weight loss outcomes in patients with pain. Obesity (Silver Spring) 23:1778-1784, 2015

20. Mauro M, Taylor V, Wharton S, Sharma AM: Barriers to obesity treatment. Eur J Intern Med 19:173-180, 2008

21. Ogden CL, Carroll MD, Kit BK, Flegal KM: Prevalence of childhood and adult obesity in the United States, 2011-2012. JAMA 311:806-814, 2014

22. Parker SL, Adogwa O, Paul AR, Anderson WN, Aaronson $\mathrm{O}$, Cheng JS, et al: Utility of minimum clinically important difference in assessing pain, disability, and health state after transforaminal lumbar interbody fusion for degenerative lumbar spondylolisthesis. J Neurosurg Spine 14:598-604, 2011

23. Terman SW, Yee TJ, Lau D, Khan AA, La Marca F, Park P: Minimally invasive versus open transforaminal lumbar interbody fusion: comparison of clinical outcomes among obese patients. J Neurosurg Spine 20:644-652, 2014

24. Wang YC, McPherson K, Marsh T, Gortmaker SL, Brown M: Health and economic burden of the projected obesity trends in the USA and the UK. Lancet 378:815-825, 2011

\section{Disclosures}

Dr. La Marca has served as a consultant to Globus Spine and Zimmer Biomet, and receives royalties from Globus. Dr. Park has served as a consultant to Globus, Medtronic, Biomet, and NuVasive, and has received royalties from Globus.

\section{Author Contributions}

Conception and design: Park. Acquisition of data: Park, Joseph, Smith, Kahn, Liu, La Marca. Analysis and interpretation of data: all authors. Drafting the article: Joseph, Farooqui, Smith, Kahn. Critically revising the article: Park, Joseph. Reviewed submitted version of manuscript: all authors. Approved the final version of the manuscript on behalf of all authors: Park. Study supervision: Park, La Marca.

\section{Correspondence}

Paul Park, Department of Neurosurgery, University of Michigan, 1500 E Medical Center Dr., Rm. 3553 TC, Ann Arbor, MI 481095338. email: ppark@med.umich.edu. 